\title{
How Diversity Matters in the US Science and Engineering Workforce: A Critical Review Considering Integration in Teams, Fields, and Organizational Contexts
}

\author{
LAUREL SMITH-DOERR \\ UNIVERSITY OF MASSACHUSETTS, AMHERST \\ SHARLA ALEGRIA \\ UNIVERSITY OF CALIFORNIA, MERCED \\ TIMOTHY SACCO \\ UNIVERSITY OF MASSACHUSETTS, AMHERST
}

\begin{abstract}
How the race and gender diversity of team members is related to innovative science and technology outcomes is debated in the scholarly literature. Some studies find diversity is linked to creativity and productivity, other studies find that diversity has no effect or even negative effects on team outcomes. Based on a critical review of the literature, this paper explains the seemingly contradictory findings through careful attention to the organizational contexts of team diversity. We distinguish between representational diversity and full integration of minority scientists. Representational diversity, where organizations have workforces that match the pool of degree recipients in relevant fields, is a necessary but not sufficient condition for diversity to yield benefits. Full integration of minority scientists (i.e., including women and people of color) in an interaction context that allows for more level information exchange, unimpeded by the asymmetrical power relationships that are common across many scientific organizations, is when the full potential for diversity to have innovative outcomes is realized. Under conditions of equitable and integrated work environments, diversity leads to creativity, innovation, productivity, and positive reputational (status) effects. Thus, effective policies for diversity in science and engineering must also address integration in the organizational contexts in which diverse teams are embedded.
\end{abstract}

\section{Keywords}

diversity; integration; US science and engineering workforce; gender equity; team science

${ }^{1}$ Laurel Smith-Doerr, Email: 1smithdoerr@soc.umass.edu

2Sharla Alegria, Email: salegria2@ucmerced.edu

3. Timothy Sacco, Email: tosacco@soc.umass.edu

Copyright (c) 2017 (Laurel Smith-Doerr, Sharla Alegria and Timothy Sacco). Licensed under the Creative Commons Attribution Non-commercial No Derivatives (by-nc-nd). Available at estsjournal.org. 


\section{Introduction}

In a full page advertisement in the pro-business magazine Forbes in April 2016, Monsanto Corporation, a sponsor of the National Diversity Council, claimed: "Bringing together diverse perspectives, experiences, ideas and opinions is the most effective way to develop creative solutions to some of the world's biggest challenges. Together we are working for sustainable agriculture." The accuracy of Monsanto's claims about sustainability aside, this ad demonstrates an important reality about scientific and technological workplaces. Even organizations like Monsanto and Forbes take for granted the idea that diversity pays dividends in innovative problem solving. Much of the literature on diversity in science teams addresses the question of whether diverse teams outperform homogenous teams; companies like Monsanto use profit maximization as a logic for why diversity on teams is a goal. Asking why diversity is a goal, however, assumes that justification is required.

The question of why or why not foster diversity on science teams is a false choice. It is a practical reality that the pool of qualified potential scientific workers in the US is increasingly diverse. Women have made up half of science and engineering college degree recipients since the late 1990s, and by 2012 about 20\% of the S\&E college degree recipients were members of underrepresented minority groups in the US (NSF 2015). In other words, more than half of the graduates with S\&E degrees in the US currently are women and / or ethnic/racial minorities. Thus, we focus our literature review not on whether organizations should assemble diverse teams, but on how - the conditions under which diverse teams perform better.

In early 2016, the US Office of Science and Technology Policy put out a call to the scientific community to comment on the "evidence based case around diversity." We responded to the call by delving deeply into the research literature and found it to be fraught with contradiction. Some studies find that diverse teams outperform more homogenous teams while others do not. Our journey through the literature demonstrated a critical difference between diversity as the simple presence of women and minority scientists on teams and in workplaces, and their full integration. We distinguish between representational diversity and full integration of minority scientists. Representational diversity, where organizations have workforces that match the pool of degree recipients in relevant fields, is a necessary but not sufficient condition for diversity to yield benefits. We will argue that full integration of minority scientists (i.e., including women and people of color) in an interaction context that allows for more level information exchange, unimpeded by the asymmetrical power relationships that are common across many scientific organizations, is required to realize the full potential for diversity to have innovative outcomes.

In our review of the literature we find that while intellectual diversity generally yields positive scientific outcomes, minority workers must be integrated-both in sufficient numbers and in organizational spaces that involve non-hierarchical interactions on teams-in order for racial and gender diversity to yield benefits (Joshi and Roh 2009; Woolley et al. 2010). We argue that part of the confusion about whether diversity matters stems from conflating diversity and integration and failing to look beyond demographic profiles at how teams actually work (or fail to work) 
together. In this review, we explore some of the reasons why we believe the diversity in science literature contains contradictory results on its benefits, examine studies that help to make sense of the contradictions, and offer practical suggestions for policymakers, academics, and business managers in moving forward with diverse science teams.

\section{Contradictions in the Literature}

Sometimes diversity is negatively associated with productivity, other times it is positively associated with productivity, and in yet other studies, there is no significant effect of diversity. How can we make sense of these contradictions? Our approach to the science team diversity literature attempts to make sense of the contradictions by considering the organizational and field level contexts in which diversity matters. To preview our argument, we find that integration is an important context for diversity. When men and women, and people of different racial and ethnic groups, are more evenly represented and more fully integrated in the organizational contexts that surround teams (field, sector, occupations, organizations, informal networks), team diversity is more likely to have positive outcomes. Based on our analysis of the research literature, we argue that integration is critical for any kind of diversity to yield benefits. We consider a team to be integrated when each member is able to fully contribute their ideas, which are heard and considered by all other team members.

First, let's be clear about what diversity means. Part of the confusion about the effects of diversity derives from imprecise uses of the term. In the context of science teams, diversity sometimes refers to the gender and racial/ethnic make-up of a team, or demographic diversity, and other times diversity refers to the cognitive approach and disciplinary background of team members, or intellectual diversity. Thus, a team made up of white men with PhDs from different scientific fields would be diverse in some studies, while a mixed gender and / or race team of people with PhDs in the same field would be considered diverse in other studies.

The academic research literature on intellectual diversity finds very clear positive effects. Intellectual diversity is beneficial for problem solving and creativity (Page 2007; Reagans and Zuckerman 2001). When intellectually diverse teams work together, they are consistently better at problem solving than homogenous teams. This finding holds even when the intellectually diverse teams are a group of novices and the homogenous teams are experts (Page 2007; Hackett and Rhoten 2009). Experimental and simulation-based tests for the effects of intellectual diversity on creativity show that the collective ability of a group is greater than individual abilities. This collective benefit is the result of diverse teams generating a broader range of potential solutions to a problem (Page 2007; Woolley et al. 2010).

Unlike intellectual diversity, the results from research on demographic diversity are less clear cut (Jackson, Joshi, and Erhardt 2003; Joshi and Roh 2009; Reagans and Zuckerman 2001;

"Adding to the confusion, the term diversity also has colloquial uses. Colloquially, "diverse" may be an attempt to politely describe individuals who are members of underrepresented racial/ethnic minority groups, especially women of color. Another colloquial usage of "diversity" seems to mean virtually any way that people differ-thus a team might be considered diverse because its members have different tastes in music. 
Harrison and Klein 2007). Studies examining publication impact, productivity, and profitability have found that diverse teams or organizations produce better results (Herring 2009; Kalev 2009; Freeman and Huang 2014). Yet other studies using similar data suggest opposite findings that demographically diverse teams and organizations do not outperform their homogenous counterparts (see Joshi and Roh 2009 for an overview).

A fundamental reason why we might expect diverse teams to outperform homogeneous ones is because demographic diversity should increase intellectual diversity (Page 2007; Freeman and Huang 2014; Reagan and Zuckerman 2001). Team diversity on a research project may mean that each researcher's ideas will be challenged, which helps the team avoid the common problem of groupthink. Demographically diverse groups often include people with very different life experiences that translate into a greater diversity of ideas on the team.

Diverse teams are also likely to have more expansive social networks. The different network locations of diverse team members provide opportunities to access different sources of knowledge, and larger audiences for dissemination (Burt 2004). This logic mirrors Granovetter's (1973) classic finding of the strength of weak ties in job searches. Granovetter discovered that men were more likely to find jobs through their acquaintances (weak ties) rather than family and close friends (strong ties). Strong ties have redundant information; that is, close friends have much the same information that you do, and therefore the new information needed to find a job is likely to come from your distant ties. A diverse research team operates in a similar way; a more diverse group of people have access to non-redundant information about the organization they work in, and less overlapping knowledge and resources. The ideas and other output that a diverse team produces is thus more likely to reach a wider array of audiences. Intellectual diversity does pay productivity dividends consistently, but while demographic diversity and intellectual diversity should logically be related, the findings about the effects of demographic diversity are mixed. Why?

\section{By the Numbers: Representational Diversity}

Much of the literature exploring the effects of diversity comes from business and management scholarship (e.g. Jenh, Northcraft, and Neale 1999; Cox and Beale 1997). The main focus of this research literature is to determine whether diversity improves companies' profitability. Several helpful studies move beyond the question of whether or not diverse teams are better to investigate mechanisms by which diversity leads to innovation and productivity.

One question is whether team cohesion leads to greater productivity. Reagan, Zuckerman, and McEvily (2004) and Reagan and Zuckerman (2001) identify two mechanisms that may cause diversity to lead to higher or lower productivity on R\&D teams. The first is that denser, more cohesive teams tend to be more productive than looser, less cohesive teams. The second is that teams whose members have non-redundant access to information and resources also tend to be more productive. The problem is these two mechanisms differ in their association to demographic diversity. More cohesive teams tend to be more homogeneous but with redundant information and resources are less likely to be innovative. The teams that have access to non-redundant information 
are more likely to be diverse but less cohesive (with trust perhaps taking longer to build, we surmise).

This tension may arise in part from the contexts in which teams work. Joshi and Roh's (2009) meta-analysis finds that the gendered categorization of a field is an important predictor as to whether gender diversity will have positive or negative effects on team performance. They find in fields like engineering that are classified as "masculine," higher rates of gender diversity on teams do little to improve performance outcomes in corporate settings. Another study by Joshi (2014) confirmed that the most productive teams were those in which women were well integrated, and were located in fields that had higher representation of women scientists (i.e., not masculine fields). Generally, the sciences have inadequate representation from women and minority groups (Fox et al. 2011), and this lack of representational diversity affects the relationships among researchers on a team. What is the experience of women scientists who work in masculine fields? For effective integration to occur in these contexts, there must be healthy informal relationships between team members. The informal relationships within an organization often translate to more formal benefits for individuals in evaluation and decision making. That is why when women academics in masculine fields are able to establish informal relationships with colleagues, they are more likely to be favorably evaluated for tenure and promotion (Fox 2015). This kind of informal integration in work contexts appears to be key for having one's work recognized as a minority or woman scientist. By definition, the effective integration of diverse teams means that the ideas of all members are heard and recognized.

A related, fruitful line of research looks at academic science and whether disciplinary contexts with higher representation of women are more conducive to producing the benefits of diversity. Cain and Leahy (2014), for example, examine disciplines with varying degrees of gender representation. In their study of psychology, life sciences, engineering, and physics, the authors find that women were able to foster stronger informal relationships with male colleagues in disciplines where they had more representation and did not embody "token" status. In disciplines where women were still underrepresented, fostering informal relationships among colleagues was more difficult. Informal relationships are an important mechanism by which diverse teams are integrated. Thus when women and scientists from underrepresented minority groups are integrated in work contexts through informal relationships with all of their colleagues, productive outcomes can be realized. The context of diverse teams matters.

Readers may have noticed that the referent for diversity in this discussion has been mainly gender. This focus reflects that of the existing literature, as can be seen in other recent reviews of research on diversity in science that focus exclusively on gender (Nielsen et al. 2017; Elsevier 2017). While our illustrations come from existing research (mostly on gender), we posit that all kinds of diversity need to be fully integrated at the interaction level for its potential to be fully realized. Interaction level integration means that each team member's voice is heard and heeded. Racial and ethnic diversity are just as important to integrate on scientific teams as gender diversity, and we know from literature on the intersection of race and gender that the experiences of women of color are not the same as those of white women or men of color in the workplace (Alegria and Branch 2015). More research needs to be conducted that references all kinds of diversity (including the 
intersection of identities) such as: gender, race, ethnicity, sexuality, physical ability, and age. That said, the existing research does suggest that minority representation is an important condition for diverse teams to outperform their homogenous counterparts. We consider representation to be a necessary but not sufficient condition for diversity to have positive effects on productivity.

\section{Integration of Diverse Teams}

Additional research shows that simply having minority workers and scientists present is not enough; all members need to be fully integrated into the work interactions to be able to contribute optimally to the team (Berdahl and Anderson 2005; Woolley et al. 2010; Smith-Doerr et al. 2016; Pezzoni et al. 2016; Macaluso et al. 2016). As we discuss below, team diversity is closely tied to interaction at the group level.

Gender diversity on teams leads to positive outcomes in group interactions. Berdahl and Anderson (2005) investigated how leadership was practiced differently by teams of men and women. The authors found groups composed of women exhibited stronger communication between group members, and also had higher participation from all members of the group. In contrast with the teams of men studied, the teams of women also developed less rigid hierarchies, with no single person taking on the position of team leader. Similarly, Woolley and colleagues (2010) found that gender diversity was a strong predictor of a group's "collective intelligence." Collective intelligence is a measure of how much better a group is at solving problems than the sum of how its individual members have previously tested. Mirroring Berdahl and Anderson's study, Woolley and colleagues found that teams with a higher percentage of women were more equitable in the dynamics of conversations and overall participation by team members. One dynamic that Woolley and colleagues investigated was interruptions during group interactions. In groups composed of all men, interruptions were a positive predictor of team performance. Conversely, in groups of all women, interruptions were a negative predictor of how groups would perform. But easier communication in single gender teams does not mean that better ideas come out of those teams. In light of studies described in the section above that suggest diverse teams are likely to be more effective and productive, it is important to consider how different styles of interaction by gender can hinder the potential benefits of diversity. Taking the findings about gender and communication styles into consideration with the findings on productivity in mixed gender groups, we conclude that for gender diverse groups to be effective, the interaction context is key.

Even within integrated contexts where the benefits of diversity should abound, power and hierarchy still matter. Power is a relational process that generates inequalities along lines of demographic diversity. Understanding how power shapes relationships and interactions is integral to understanding the complexities and nuances of the contexts in which diverse research teams can thrive. The findings described from observations of lab meetings by Smith-Doerr, Sacco, and Stoughtenburgh (2016) highlight this tension in contexts where diversity should have clear benefits and yet the interactional power dynamics mitigate potential benefits. Drawing on ethnographic data collected in four settings, the authors analyze 72 lab presentations-36 by men 
and 36 by women. Young women, early in their scientific careers, display a crisis of confidence. Lack of confidence was seen in physical nervousness, fidgeting, stumbling over words, labored breathing, apologizing for minor things, and saying outright that one was nervous. During lab presentations, young women displayed 45 instances of a crisis of confidence compared to only 7 instances by young men. This tendency for young women to display a crisis of confidence came across as instinctive, but analysis of the data revealed the interaction context, and power dynamics that elicited this gendered display.

When interaction contexts occur within hierarchical structures, the potential benefits of diversity may be difficult to achieve. Integration relies on equal exchange, and hierarchies often shape interactions to be unequal. As with the findings from Woolley et al. (2010), Smith-Doerr and colleagues (2016) found a gender difference in interruptions during interactions. During lab presentations young women were much more likely to be interrupted than their young men counterparts. When young men had lapses in a presentation, PIs and other faculty would commonly joke with them about the occurrence. For young women, on the other hand, the instances were treated more seriously, as a crisis. Faculty were much more likely to jump in and "save" young women. When tough questions were asked, PIs would regularly answer questions for young women, or expand on what they said to further explain complex concepts. When these "saves" occurred, Smith-Doerr and colleagues observed that they often compounded already negative experiences of young women, causing them to get increasingly flustered and nervous. The labs studied by Smith-Doerr and colleagues were integrated spaces, where the inclusion of both men and women in the research groups should, hypothetically, have positive benefits on the research. But the academic hierarchical context of social interaction was detrimental to young women in ways their young men colleagues did not experience.

These findings from a qualitative study of labs are complemented by quantitative findings by Pezzoni and colleagues (2016), who investigate how different gender configurations matter for productivity of academic research teams. Studying the publication output of six cohorts of $\mathrm{PhD}$ students, the authors investigate how different gender pairings in advisor/advisee relationships influence students' publication output. While homogenous pairings of men and women had no significantly different effects on productivity, men students working with women faculty published 10\% more than those working with men faculty. But gender diversity's positive effect was contingent on who was in the authority relationship: women students working with men faculty published $8.5 \%$ less than men students working with men faculty. These results are magnified when impact factors of the journal publications are considered. Taken together, the studies by Smith-Doerr et al. (2016) and Pezzoni et al. (2016) indicate that the academic hierarchy is a context that shapes the effects of gender diversity. When women are in powerful positions, they have an opportunity for greater productivity in diverse teams. But when male power aligns with academic authority, young women training to be scientists are at an extreme disadvantage in the interaction context of research teams.

Another recent study that demonstrates the difficulty of full integration in team interactions focuses on co-authorship roles. Macaluso and colleagues (2016) found that even on publications with gender integrated teams, there was often an asymmetrical division of labor 
reported for the work of men and women. The study used the Public Library of Science (PLOS) to examine who performed different tasks. For the seven PLOS journals, each author was required to report their contribution to a manuscript from a list of different categories. Women were most often associated with running experiments while men were most likely to be associated with writing papers. The article-aptly titled "Is Science Built on the Shoulders of Women?"--concludes that there are enormous gender inequalities in the labor roles in science, and stronger systems for reporting the division of labor are needed.

The outcomes of diversity are described in a range of ways in the research literature. Studies of team diversity are typically concerned with investigating the outcomes that diversity has on team performance, although "outcomes" have been measured in many different ways including: potential for innovation (Freeman and Huang 2014), ability to problem-solve (Page 2007; Reagans and Zuckerman 2000), and links to corporate productivity (Kalev 2009). We draw on the existing literature in making our case-which is a different argument about the need for diversity to be fully integrated in work contexts-rather than focusing on one specific outcome of diversity, or how certain kinds of diversity are linked to specific outcomes.

In as much as the outcomes focused scholarship on team diversity looks at integration, this research suggests there are significant productivity benefits to integrated teams. However, outcomes-oriented scholarship misses the relational dynamics that generate inequality at the interactional level. The mere presence of women and underrepresented minority scientists is not, in itself, sufficient to ensure that these scientists are able contribute their ideas, knowledge, and resources. Teams need both representative diversity and interactional integration to benefit fully from diversity.

\section{What We Know So Far}

The research on diversity in science clearly shows benefits from intellectual diversity. The same mechanisms that produce benefits from intellectual diversity should also theoretically lead to benefits from demographic diversity. Under conditions of greater integration, such as when fields are gender balanced, demographic diversity does often yield benefits. But even when teams are more demographically diverse, if the power structures relegate women and people of color to the bottom of the hierarchy, this is not true integration and the benefits of diversity will not be realized. Thus, we conclude that, when all team members can contribute fully, demographic diversity can be expected to improve productivity, problem solving, and innovation. In other words, it is not enough to simply add minority scientists to teams, the organizational context must be structured for those scientists' ideas to be valued.

The organizations that can accomplish this kind of diversity will likely have competitive advantages in both productivity and status or prestige. Herring (2013) demonstrated that the most prestigious academic sociology departments are also the most diverse. Presumably, these departments have faculty whose ideas are recognized and valued by their colleagues. And critically, the pool of qualified scientists is growing more diverse. 
Organizations that do not recruit and integrate minority scientists will find their potential hiring pool becoming increasingly limited. In addition to growing gender and racial diversity in US degree recipients, the number of scientists and engineers moving from overseas to work in the US has grown steadily over recent decades (Alegria and Branch 2015). By simple numerical counts of qualified workers, teams should be diverse. The literature that compares outcomes for homogenous and heterogonous teams implicitly assumes that both are options and organizations can simply choose the one more likely to maximize profits. While this assumption allows diversity research to make persuasive claims with clear directives for the business world, it ignores real world constraints and has the potential to validate discrimination. Diversity is a practical reality of the contemporary US workforce-savvy organizations will focus on how they can maximize their innovative capacity by building fully integrated diverse teams.

Much of the research on team diversity comes from the management literature. Thus, while we focus on science teams, we draw on research that reaches outside of university and research institute settings into the for-profit corporate sector. Many scientific and technical workers in industry do team science; however, while the work may be similar the conditions are not the same as academic settings. Industry workers rarely have the autonomy to pick projects and collaborators that academic scientists enjoy. This may actually make industry more amenable to changes that support integrated teams since science teams in industry can actually be selected for their diversity and guidelines for interactions can give teams practical direction for fully incorporating all team members. On the other hand, teams in the corporate world tend to form to complete discrete projects; when the project ends so does the team. Reagans and Zuckerman's (2001) findings that stronger ties between team members leads to more productive teams suggests that diverse teams may need longer to build the stronger ties than homogeneous teams. Academic researchers have more freedom to sustain research collaborations over long periods, which might help them to develop stronger ties across differences.

\section{Practical Matters}

The main implication of the knowledge base covered by this review is that integration-having good representation of people from diverse backgrounds and integrating their work at all levels (fields, organizations, occupations, and teams)—results in positive outcomes. Increasing the numbers of women and people of color where they are underrepresented, in an interaction context that integrates diverse contributions, will have positive effects. A central practical question is then: How to increase integration? In this final section we take information from our critical analytic review of the literature but step aside from analysis to practical matters. We seek to develop a conversation here that has implications for three different audiences: 1) science policymakers, especially in the US national context, 2) decision makers in organizations, especially in the private sector, and 3) scholars, especially in STS and the social sciences. 


\section{For Science Policymakers}

Given the central findings that gender and racial integration of scientific workplaces leads to positive outcomes, integration should be a key goal for science policy. Our key message to policymakers about broadening participation of women and underrepresented minority scientists and engineers is: Presence is a necessary (if not sufficient) condition for integration. The fact that having one or two women or people of color in a workplace is not sufficient for integration is an argument that goes back to Kanter's (1977) discussion of the detrimental effects of tokenism. Women who are tokens in a work context, like the women managers studied by Kanter (1977), often find themselves to be stereotyped, facing pressures to represent all women and yet ironically may be invisible in a sea of men coworkers. Tokens are often stereotyped, face performance pressures as representing an entire population of people rather than their own opinion, and yet ironically may also be overlooked (Kanter 1977). Kanter's theory of tokenism posited that a critical mass of a minority group needed to be over $15 \%$ of the workplace for the effects of being a token to be mitigated. Other research has also found that a critical mass of women in science is important for integration and a hospitable climate (Etzkowitz, Kemelgor, and Uzzi 2000; Fox, Whittington, and Linkova 2017; Belle et al. 2014). Policymakers should develop ways of encouraging fields, disciplines, and scientific organizations to look like the general national population. This effort will pay off in better knowledge production.

\section{For Corporate Decision Makers}

What should be done in the meantime for organizations or fields that are not yet integrated? One, do not let up on efforts to develop policies that will increase representation that better matches the population. Two, consider ways that diversity might be concentrated in organizations and places where transformation might occur and lead the way. A study by Reagans and Zuckerman (2001) suggests one potential approach. In that study, an R\&D team's social network density is measured by both the presence of ties and the frequency of communication. Dense networks have easier coordination, but less dense networks that span diverse groups which would be otherwise disconnected allow for more learning. The authors argue that local density on teams is needed for coordination (and probably trust, we would add), and that diversity in a global network-that is, in a wider context like an organization or field-produces innovative outcomes if there are some bridging ties between teams. One potential implication is that fostering demographic diversity across sets of strongly tied research teams may have positive effects, even if not every team is diverse. This approach could be a starting point for building greater diversity across all teams, and as a recruiting tool.

From the organizational sociology literature on diversity initiatives and programs in the private sector we know at least as much (and perhaps more) about what not to do, as about what to do to increase integration. Frank Dobbin and Alexandra Kalev's (2016) work on corporate implementation of various affirmative action and diversity programs shows that diversity training may actually result in less integration and more grievances filed. Likewise, recent research (Edelman and Galanter 2014; Bingham and Scherer 2001) notes that sexual harassment training 
may result in more sexual harassment. Programs aimed at educating workers about compliance with formal policies are not effective. We know from nearly one thousand peer reviewed studies that enforced rules, like diversity training, actually have the opposite effect and instead elicit bias and backlashes against integration efforts (Dobbin and Kalev 2016). These kind of rule-based, negative enforcement efforts threaten managers' autonomy. Another often used approach to diversity that does not work are supposedly neutral metrics like hiring tests and performance ratings, because biases get built into the evaluations (Acker 1989; Rivera 2012). And finally, grievance procedures do not lead to diversity because retaliation by managers against employees who file grievances outweighs any curbing of bad behavior (Dobbin and Kalev 2016).

Fortunately, in addition to demonstrating what doesn't work, Dobbin and Kalev (2016) also provide insights into what does work for integrating a diverse workforce in the corporate sector. Engaging powerful managers in the work of integration is highly effective. Mentoring and sponsorship programs for women and minority managers have positive effects. Cross group contact is also effective in building integration. Targeted college recruitment and task forces have positive effects on integration because engaging people in positive action toward a goal like diversity often leads to changes in beliefs and attitudes. In addition, having some kind of social accountability-perhaps tying managers' reputations to looking fair-could be an effective tool for integration.

\section{For Scholars}

For STS scholars and social scientists, we would call for a fundamental change in how diversity research is conducted. A reflexive view is needed to see that how we study diversity matters. There is a need for more rigorous theoretical development and critical analysis of diversity research itself. As we discussed above, we see a fatal flaw in the status quo assumptions of research on diversity: in making an argument for why diversity, there is an assumption that continuing with a fundamentally unequal, segregated science and technology workforce is an option. This status quo assumption is not good critical thinking, and worse, may have the unintended consequence that perhaps by studying diversity we are complicit in maintaining inequality. How can we advocate for equity and diversity while working within existing power structures and hierarchies? We have a range of opinions about this question even among our own author group. For example, we began this essay with a quote from Monsanto. Is there room to engage with corporations on diversity? We think there is space for a range of responses in STS. Some of us need to be outside of the system, working with social movements and activists. Others of us need to be inside the system, shaping the use of diversity research so that organizations and policies can effectively shift the status quo rather than continuing with ineffective approaches. The breadth of STS and the range of critical approaches to science and technology mean that there is no one best way to engage. 


\section{Conclusion}

The question of whether team diversity increases or decreases productivity misses the mark. Diversity in the science and engineering workforce is a fact, and organizations need to be asking how to integrate the contributions of all members of diverse teams in order to reach their potential for greater productive and innovative outcomes. As we wrap up this writing in 2017, almost exactly one year after we presented our review and argument at the White House Office of Science and Technology Policy, much has changed. A new presidential administration has raised questions about the extent to which diversity is taken for granted as beneficial, and even about the future of support for science in the US. Although we may now be in a different political moment, the fundamental problem remains the same, and we think it transcends partisan politics: if organizations and fields (and nations) cannot include all scientists, they will flounder.

Thus in the section above we offer some thoughts about how organizations in the private sector, policymakers in the public sector, and academics in our world might take forward the lessons about integrating diversity into their work. In addition to these initial thoughts, we see a need for more research and understanding of where the industry, government, and academic sectors overlap and can collaborate on integrating racial and gender diversity (and other kinds of diversity) in order to produce better knowledge and technologies. Another set of research questions concern intersectionality, and how systems of exclusion and social closure that are barriers to integration (like gender and racial orders) are not separate social forces but overlap and create different challenges for white women and women of color, for example. The science workforce is diverse, and organizations (and nations) that can integrate diverse teams of scientists will be the most productive, creative, and able to solve problems.

\section{Acknowledgements}

The authors would like to acknowledge our thanks for the opportunity to present these ideas at the White House Office of Science and Technology Policy in March 2016, and for helpful discussion before that presentation in February 2016 at Stanford University during an NSF funded workshop organized by Mathias Nielsen and Londa Schiebinger.

\section{Author Biography}

Laurel Smith-Doerr is the Director of the Institute for Social Science Research and Professor of Sociology at the University of Massachusetts, Amherst. Her research examines how organizations shape inequalities and knowledge production. She is one of the editors of the 2017 Handbook of Science and Technology Studies, Fourth edition, Cambridge, MA: MIT Press. 


\section{Author Biography}

Sharla Alegria is an Assistant Professor of Sociology at the University of California, Merced. Her research examines inequalities that persist when individuals and organizations embrace principles of equity. She has received funding from the National Science Foundation, University of Massachusetts Graduate School, and the Anita Borg Institute.

\section{Author Biography}

Timothy Sacco is a doctoral candidate in Sociology at the University of Massachusetts, Amherst. His dissertation research is an ethnographic investigation into how the commercialization of science shapes educational and research settings. His research is supported through an NRT grant from the National Science Foundation.

\section{References}

Acker, J. 1989. Doing comparable worth: Gender, class, and pay equity. Philadelphia: Temple University Press.

Alegria, S. and E. H. Branch. 2015 . "Causes and Consequences of Inequality in the STEM: Diversity and its Discontents." International Journal of Gender, Science, and Technology. 7(3): 321-342.

Belle, D., L. Smith-Doerr, and L. M. O'Brien. 2014. "Gendered Networks: Professional Connections of Science and Engineering Faculty." Pp. 153-175 in Gender Transformation in the Academy (Advances in Gender Research, Volume 19), edited by V. Demos, C. W. Berheide, M. T. Segal. Emerald Group Publishing Limited.

Berdahl, J. and C. Anderson. 2005. "Men, women, and leadership centralization in groups over time." Group Dynamics: Theory, Research, and Practice 9(1): 45-57.

Bingham, S. and L. Scherer. 2001. "The Unexpected Effects of a Sexual Harassment Educational Program." Journal of Applied Behavioral Science 37(2): 125-153.

Burt, R. S. 2004. "Structural holes and good ideas." American Journal of Sociology, 110 (2): 349-399. Cain, Cindy L., and Erin Leahy. 2014. "Cultural Correlates of Gender Integration in Science." Gender Work and Organization 21(6): 516-530.

Cox, T., and R. L. Beale. 1997. Developing Competency to Manage Diversity. San Fransisco CA: BerrettKoehler.

Dobbin, F. and A. Kalev. 2016. "Why Diversity Programs Fail, and what works better." Harvard Business Review July-August 2016: 52-60.

Edelman, L. B. and M. Galanter. 2014. "Law: The Socio-Legal Perspective." International Encyclopedia of the Social and Behavioral Sciences, $2^{\text {wa }}$ edition. Elsevier.

Etzkowitz, H., C. Kemelgor and B. Uzzi. 2000. Athena Unbound: The advancement of women in science and technology. New York: Cambridge University Press. 
Elsevier. 2017. Gender in the Global Research Landscape. Available at: https:// www.elsevier.com/_data/assets/pdf_file/0008/265661/ElsevierGenderReport final_for-web.pdf.

Fox, M. F., G. Sonnert and I. Nikiforova. 2011. "Programs for Undergraduate Women in Science and Engineering: Issues, Problems, and Solutions." Gender \& Society 25: 589-615.

Fox, M. F.. 2015. "Gender and Clarity of Evaluation among Academic Scientists in Research Universities." Science, Technology and Human Values 40(4): 487-515.

Fox, M. F., K. Whittington and M. Linkova. 2017. "Gender, (In)equity, and the Scientific Workforce." Chapter 24 in the Handbook of Science and Technology Studies, 4th edition, edited by U. Felt, R. Fouche, C. Miller, and L. Smith-Doerr. Cambridge, MA: MIT Press.

Freeman, R. B. and W. Huang. 2014. "Collaboration: Strength in Diversity." Nature 513 (7518): 305.

Granovetter, M. S. 1973. “The Strength of Weak Ties." American Journal of Sociology 78(6): 1360 1380.

Hackett, E. and D. Rhoten. 2009. "The Snowbird Charrette: Integrative interdisciplinary collaboration in environmental research design." Minerva 47(4): 407-440.

Harrison, D. A. and K.J. Klein. 2007. "What's the difference?: Diversity constructs as separation, variety, or disparity in organizations." Academy of Management Review 32(4): 1199-1228.

Herring, C. 2009. "Does diversity pay?: Race, gender, and the business case for diversity." American Sociological Review 74(2): 208-224.

Herring, C. 2013. "Critical Diversity and Departmental Rankings in Sociology." American Sociologist 44: 267-281.

Jackson, S. E., A. Joshi and N. L. Erhardt. 2003. "Recent research on team and organizational diversity: SWOT analysis and implications." Journal of Management 29(6): 801-830.

Jenh, K. A., G. B. Northcraft and M. I Neale. 1999. "Why differences make a difference: A field study of diversity, conflict, and performance in workgroups." Administrative Science Quarterly 44: 741-763.

Joshi, A. and H. Roh. 2009. "The role of context in work team diversity research: A meta-analytic review." Academy of Management Journal 52(3):599-627.

Kalev, A. 2009. "Cracking the Glass Cages? Restructuring and Ascriptive Inequality at Work." American Journal of Sociology 114(6): 1591-1643.

Macaluso, B., V. Lariviere, T. Sugimoto and C. R. Sugimoto. 2016. "Is Science Built on the Shoulders of Women? A Study of Gender Differences in Contributorship." Academic Medicine 91(8): 1136-1142.

National Science Foundation. 2015. Women, Minorities, and Persons with Disabilities in Science E Engineering. Arlington, VA: NSF 15-311.

Nielsen, M. W., S. Alegria, L. Börjeson, H. Etzkowitz, H. J. Falk-Krzesinski, A. Joshi, E. Leahey, L. Smith-Doerr, A. W. Woolley and L. Schiebinger. 2017. "Gender diversity leads to better science." Proceedings of the National Academy of Sciences 114 (8): 1740-1742

Page, S. E. 2007. The Difference: How the Power of Diversity Creates better Groups, Firms, Schools, and Societies. Princeton, NJ: Princeton University Press. 
Pezzoni, M., J. Mairesse, P. Stephan and J. Lane. 2016. “Gender and the publication outputs of graduate students: A case study." PLOS One 11(1): 1-12.

Reagans, R. and E. W. Zuckerman. 2001. "Networks, diversity, and productivity: The social capital of corporate R\&D teams." Organization science 12(4): 502-517.

Reagan, R., E. Zuckerman and B. McEvily. 2004. "How to make the team: Social networks vs. demography as criteria for designing effective teams." Administrative Science Quarterly 49(1): $101-133$

Rivera, L. A. 2012. "Hiring as Cultural Matching: The Case of Elite Professional Service Firms." American Sociological Review 77: 999-1022.

Smith-Doerr, L., J. Croissant, I. Vardi and T. Sacco. 2016. "Epistemic Cultures of Collaboration: Coherence and Ambiguity in Interdisciplinarity." In Investigating Interdisciplinary Collaboration: Theory and Practice Across Disciplines, edited by S. Frickel, M. Albert and B. Prainsack, 65-83. New Brunswick, NJ: Rutgers University Press.

Smith-Doerr, L., T. Sacco and A. Stoutenburgh. 2016. "Crisis of Confidence: Young women doing gender and science." In Pathways, Potholes, and the Persistence of Women in Science: Reconsidering the Pipeline, edited by E. H. Branch, 95-111. Lanham MD: Lexington Books.

Woolley, A. W., C. F. Chabris, A. Pentland, N. Hashmi and Thomas W. Malone. 2010. "Evidence for a collective intelligence factor in the performance of human groups." Science 330: 686688. 